\title{
Faculty Perspectives in the Transition to Online Teaching
}

\author{
Jo-Anne H. Willment \\ Myra Baynton \\ Janet Groen \\ Lorraine Slater \\ University of Calgary
}

\begin{abstract}
This study explores the experiences of faculty new to distance learning across two faculties within a mid-sized Canadian university. An interview and thematic analysis methodology produced results that identified six themes critical in the transition to online teaching. These include: instructors' affect, organizational culture and context, multifocused supports, time, instructor role identity, and coping strategies. The paper concludes with recommendations for the development of a national distance education framework for instructors transitioning from face-to-face to online teaching in Canadian colleges and universities.
\end{abstract}

\section{Résumé}

Cette étude explore les expériences des professeurs qui enseignent à distance pour la première fois dans deux facultés d'une université canadienne de taille moyenne. Des entrevues et une analyse thématique ont mené à l'identification de six thèmes d'importance critique pour la transition à l'enseignement en ligne. Ces thèmes sont la dimension émotive, la culture et le contexte organisationnels, les divers types d'appui, les préoccupations par rapport au temps, l'identité du rôle de l'enseignante ou de l'enseignant et les stratégies mises en æuvre pour se débrouiller dans une situation difficile. Le texte débouche sur des recommandations pour le développement d'une politique nationale en formation à distance qui encadre les formatrices et formateurs dans la transition de l'enseignement présentiel à l'enseignement en ligne dans les universités et collèges au Canada.

Jo-Anne Willment, an Associate Professor has special interests in distance education practice and policy in Canada and web-based innovations in adult education. Myra Baynton has a PhD in Adult Education, extensive background in workplace learning, human resource consulting and teaching online. Currently an e-learning specialist with the Faculty of Social Work, she designs and teaches online courses. Janet Groen, EdD is an Assistant Professor in Workplace and Adult Learning within the Faculty of Education. She is in her 4th year of teaching online and explores effective use of synchronous communication.

Lorraine Slater served as Senior Instructor in the Graduate Division of Educational Research in the Faculty of Education. She taught courses in educational leadership oncampus and through distance education. She is principal of an elementary school. 
Transition to On-Line Teaching

\section{Introduction}

Many graduate students choose to reside in their communities and continue to earn a salary at the workplace while completing a graduate degree through online education. These adult learners are extremely diverse, are interested in further professional graduate education at the master or doctoral level, and expect university faculty and instructors to be able to respond appropriately to their educational needs, goals and ambitions. This nontraditional approach to graduate professional degrees continues to expand in Canada.

To address this growing demand from adult learners, instructors need to become familiar with asynchronous and synchronous communication technologies, they need to learn how to plan and deliver online courses, they must learn ways of providing online education to engage learners, and they must develop strategies to respond to diverse learner groups. Through the acquisition of these practices, faculty are supported in their move from the traditional classroom environment to an innovative online setting.

Given the implicit demands on faculty and instructors, what are the experiences of faculty as they transition from face-to-face to the online environment? What are the implications for continuing professional education of faculty? To answer these questions, the collaborative faculty distance learning research team explored these issues from personal and professional perspectives.

Studies have documented faculty's ability to adapt and integrate teaching practice into online technology by investigating faculty participation (e.g.; Betts, 1998), factors needed for online faculty involvement (e.g.; Quinn \& Corry, 2002), and faculty adaptation to the use of educational technology (e.g.; King, 2002). A study by Baynton, Groen, Willment, \& Slater (2003) concluded that it was not only important to create and maintain meaningful support systems, but the relationship between the instructor and the instructional philosophy needed to be consistent with the ways in which faculty use technology to plan and deliver their courses.

This study explores how instructors from two faculties deal with this issue. There were two key questions examined by the study:

Question 1: What were the experiences of instructors from within and outside the faculty as they moved from face-to-face to online teaching?

Question 2: Are there similarities and differences from instructors across two faculties in the way in which they approached this first-term online learning experience? 


\section{Method}

Participation in the study was voluntary, with each research team member interviewing one or two full-time faculty instructors new to online teaching. The participants in the study included only those full-time faculty who were prepared to provide one interview to the research team over the term. The use of common questions within a semi-structured interview ensured a consistent format was used across all interviews. Each interview lasted approximately one hour and took place in the privacy of faculty offices. Interview questions were provided in advance to enable prior thinking and reflection in preparation for the interview meeting. Additional comments were also welcomed from the participants.

"By using deliberate encouragement and establishing good rapport, a researcher can obtain information participants would reveal in no other way" (Merriam \& Simpson, 1995, p. 151). To develop a degree of trust and empathy with participants, each researcher began the interview by briefly summarizing their initial teaching experiences with distance education that conveyed to participants a sense of understanding about these personal experiences. The research team was open and accepting of others' personal stories about online teaching. This approach built upon "a framework within which respondents can express their own understanding in their own terms" (Merriam \& Simpson, 1995, p. 109).

Transcripts were created from each interview and reviewed by each interviewee for edits and omissions prior to the commencement of the data analysis. This interviewing process elicited stories that were unique, insightful, detailed and resulted in a context and framework for each of the interviewee narratives. Researchers then sought to compare and contrast information across interviews, and to propose implications and future directions for faculty experiencing online teaching for the first time.

\section{Data Analysis}

All transcripts were read by each researcher, noting the (a) issues that were raised in each interview; (b) steps that each interviewee had used to prepare for their first-term of online teaching; (c) difficulties that had been experienced; (d) coping mechanisms used; and (e) the learning experiences gained from first-time online teaching. These five areas were compared across interviews producing six themes which are discussed below. To protect anonymity and confidentiality of interviewees, names have been replaced with pseudonyms. 
Transition to On-Line Teaching

\section{Results}

\section{Participant Description}

Six faculty members responsible for teaching graduate level courses participated in this study; two men and four women from education and social work within the same institution. All participants were new to instructing within an online environment, were experienced with classroom teaching, and represented a variety of experiences and backgrounds including: faculty from non-university educational settings, faculty from senior administrative positions, faculty from workplaces in industry, and senior faculty members.

\section{Instructors'Affect}

A broad range of emotions from fear, anxiety, and apprehension to excitement was expressed by participants in response to their initial experiences in teaching online. In addition, it appeared as if the instructor's feelings toward distance learning, as well as their attitudes about the quality of learning through this medium, shaded their experiences throughout the term. For example, Karen explained her initial motivations for entering into online instruction.

Actually it was about a year and a half ago that I was asked if I would consider teaching online. I'd always been very skeptical of online courses. I just thought that you missed so much from the face-to-face interaction... which is what I thrive on. But I said sure, as long as I'm going to criticize something I might as well know what I'm criticizing. So I said yes I would do that. (Karen, 5/2004)

Although Kate expressed some nervousness in starting online instruction, she felt positive about her launch into distance learning at the beginning the term.

I love it. I'd do it any time. I got into it ten-fifteen years ago in the secondary panel. I got into it from being in a rural community, so I see it as a real equality of access, a social justice issue. (Kate, 5/2004)

A cautious openness to adapting to online instruction was noted by George. In spite of some reservations, George felt it was important to continue 
with a commitment to online learning. He felt it would get easier if he could become more comfortable and relaxed with the teaching. He talked guardedly about giving up a sense of power by relying on technology to control the virtual classroom.

\section{Organizational Culture \& Context}

Each course was launched, supported, and modeled in a way that reflects a different and implicit organizational culture and context across two faculty cultures. For example, instructors explained how distance learning program was handled in their respective Faculty.

We have a mandate to deliver education to the whole province. Distance education for professional continuing education...is the only way to reach all...in the province. (Carole, 5/2004)

What's driving this is not just supports but expectations, right? We have it explicitly built into our annual reports that one of the things that's valued in teaching is use of technology and teaching. It was made pretty clear from the outset that if we use technology...this was valued by this faculty. (George, 5/2004)

In addition, bonuses were put into place within this faculty to express appreciation to those faculty members who attended additional professional development sessions in order to adapt to online instruction.

The incentive was that if you signed up to learn technology, you got a thousand bucks. If you just took the courses. And if you complete a project... and do a little presentation on your project, then you get your second...two grand.

(Karen, 5/2004)

In contrast, the other faculty did not have strong faculty-wide statements, incentives or strongly encouraging expectations to consistently communicate that a high value was placed on distance education.

There are a lot of hard things about working at the university, but that's one of the good things about it, is that 
you can actually say, you know what? I don't think this will fitfor me. (Karen, 5/2004)

People really get their backs up when it's sort of in your face [online instruction] and you have to do it. (Carole, 5/2004)

I think we have to listen to our colleagues big time whether they want to do this. Our graduate students' experiences online are very uneven. And my students were very open about that, they were very clear that some of us are doing this well and some of us really aren't. And that's not fair, that's not right. (Keith, 5/2004)

Faculty need encouragement in moving to online teaching if they are to become competent delivers of student instruction. Without clear motivators, faculty may become divided between online versus face-to-face instruction without clear direction on the role that distance education plays within their departments.

\section{Multi-focused Supports}

All interviewees recounted helpful technical assistance from technicians, distance education staff, librarians, software support personal, and others. They learned about the online processes such as the structure, templates, and multiple resources they had available to help them.

Everybody here was wonderful, they were very supportive and I have no problem with any of this. (Kate, 5/2004)

I think it is fabulous. Anytime I've asked for anything, I have received help just in time, I mean right there. I find the tech people just phenomenal... definitely worth taking advantage of all those things. (George, 5/2004)

Help from librarians and technical resource people was also privately available to instructors privately in faculty offices.

The computer I had when they first asked me to do [this course], wasn't powerful enough. And so I got the loan of a computer from the graduate division, and that was set up for me, and others helped me with other needs. I sat there in the office and I was taught how to click on this...I had no 
experience, I just did what they told me to do and it worked out pretty well. (Carole, 5/2004)

They worked very hard for me. And we got permission to put six [books] on-line. (Martha, 5/2004)

Strong support was received from formal special events that brought instructors together to discuss the ways in which to promote student learning.

We had several really interesting faculty days where we discussed student-focused learning or a learner-centered model of online teaching. (Kate, 5/2004)

This dialogue was also was evident amongst small groups of instructors who met in halls and offices. For example, some instructors exchanged their initial course syllabi with each other for informal comment and suggestions. This sharing and discussion of informal learning ideas helped to solidify and integrate these new instructor approaches.

I really appreciated being able to talk with other faculty and to talk through some of the things that I was hoping to do and having somebody else sort of validate what was happening.

(Karen, 5/2004)

One of my PhD students and a friend and colleague kicked the tires a few times to make sure [the syllabus] was ok. The actual design of that course was a rather erratic departure from other designs, I think, for distance education.

(Keith, 5/2004)

In some instances, instructors extended this support and asked students for informal feedback as they progressed through the course.

I was also very up front with the students that I was new [to the software] and I wanted their continuous feedback. I think they were very honest all the way along. I was just so fascinated with their interpretations of who I was and how I designed this, and how the experience was for them. So they were very open, and some of them were quite candid about previous online experiences they'd had. (Martha, 5/2004) 
Sources of support were discussed in rich and varied ways. In addition, ongoing student feedback throughout the course provided a mechanism for new sources of support for faculty as they adapted to the online environment.

Time

The lack of sufficient time to fully prepare for the process of teaching online was a factor identified by participants in this study. This included time to become familiar with the technology, time to learn about the benefits and varying approaches of online work, and time to attend workshops and seminars for further discussion and planning before quickly launching with unanswered questions into the design and implementation of course development.

We do help each other, it's just that you almost need more formalized opportunities to do this. (George, 5/2004)

The workload definitely gets in the way. I think technology of any kind takes time to play...we need time to play with it and feel comfortable with it. (Keith, 5/2004)

Once courses were underway, faculty reported that communicating online, teaching on-line, planning activities and dealing with unpredictable online challenges exceeded the usual three-hour a week required with face-to-face instruction. As a result, increased workloads were a faculty concern.

I went to the course, but probably not often enough. But I had so much work because I was overloaded. (Karen, 5/2004)

There was also concern expressed about the degree to which students recognized that as much time was needed for online courses as face-to-face courses. Martha summed up this issue in the following way:

That notion of workload and how we promote online learning. And when we promote online education by saying it is any time, any place, I think people still aren't making time for it. (Martha, 5/2004)

\section{Instructor Role Identity}

References to philosophy, beliefs, and values emerged within the theme of identify for instructors. According to MacKeracher (1996), the transitional 
journey to becoming online instructors requires a reworking of our past model of reality as educators. Making room for this new reality requires an internal revision of self that includes examining values and beliefs that inform self. The participants in this study, as experienced instructors in the face-to-face environment, know and understand the dynamics of successful teaching and learning and understand their role in facilitating such an environment. However, the struggle in knowing how to achieve this as an online as opposed to a faceto-face instructor was evident in the following comments:

I wasn't being me; I wasn't being me as a professor. (Keith, 5/2004)

I have a clear sense of what I want to do in the classroom and how I want to be in the classroom, but I don't on Blackboard. I don't know what I'm supposed to do. (Keith, 5/2004)

On the other hand, other instructors like Kate, suggested that moving from class to the online environment was a seamless process.

Other than a little facelessness for me, everything's pretty much transferred well. Right down to the lessons that I did in face-to-face, it's [online] a fairly equivalent class.

(Kate, 5/2004)

The issue of role ambiguity and the stress and emotional strain involved in that transitional process has been well documented in the literature related to adult learning (Cranton, 1994; MacKerarcher, 1996) and leadership (Bredeson, 1993). The need for a sense of confidence in who you are and what you are doing is noted in the following comment.

People have a concern for self first and... are interested in not looking stupid themselves and being less confident. (Carole, 5/2004)

The actual design of the course was a rather erratic departure from the other designs, I think, for distance course. So I was very nervous about how it would be received. I would say that about two or three weeks into the course I just started getting validation that I wasn't going nuts and the design was okay. (Martha, 5/2004) 
Instructors become attached to the values and beliefs that inform our sense of self (MacKerarcher, 1996; Mezirow, 2000). The strain of having one's sense of self and confidence challenged is evident in the following comment from Keith:

In my evaluation of that course from the students there were only seven of them that responded. It wasn't a good evaluation. I've never had a bad evaluation in graduate courses in my life. (Keith, 5/2004)

Finally, as participants in the study transitioned through the stages of becoming on online instructor "modifying, transforming, and reintegrating knowledge and skills" (MacKeracher, 1996, p. 37), they expressed aspects of their instructor's role that were most important to them. In describing the satisfaction and synergy that make teaching a fulfilling endeavour, two opposing personal perspectives were captured.

Teaching online was an incredible experience for me, I really enjoyed that. (Carole, 5/2004)

I'd rather work at Walmart than teach entirely in a distance program. In my mind there is no job satisfaction in that.

(Keith, 5/2004)

Data from this study indicate that instructors' pre-entry feelings and attitudes toward distance learning likely have the potential to influence their experiences throughout the term.

\section{Coping Strategies}

The importance of knowledge was cited by instructors as part of the course design discussion with our researchers. Salmon (2002) suggests that "thinking creatively involves breaking down and restructuring knowledge in order to secure new insights" (p. 137). Understanding how we create knowledge in our minds in the first place helps us to reorganize our thoughts. It was clear that presenting smaller instruction information units was a way to have students build their own understanding of knowledge in their courses.

I was very nervous about how this would be received. It was this notion of a model within a model and the experience that grows from this. I was very nervous for the first month, 
as people started doing things [in the course], and it started making sense to them how they were moving through it and experiencing it. Instead of concentrating on the design of the course, it started moving them into building knowledge around information that was there. For the first time, I began to sit back and go, "Okay, this isn't nuts, this design works." I just started getting validation. (Kate, 5/2004)

A closer examination of knowledge building through the online process revealed the following:

I built it around how individual learners could experience the information that was presented and build upon their own knowledge. And demonstrate that either in some collaborative ways or some independent ways and use the tools that we have to experience that. So the social interaction and the discussion things were not mandatory. I was much more interested in individuals coming in contact with content, doing tasks so that if the tasks required cooperation and collaboration they arranged that. I was the resource that facilitated what I like to think of [as] knowledge-building from the content and information. And it worked. If you were to do that classical tree analysis of who's doing what and when, mine likely looks different and lean. (Carole, 5/2004)

The sense of community was also identified by interviewees as an essential element in course design and delivery. Lesser, Fontaine \& Slusher (2000) indicate that electronic forms of communication can build different types of communities which might include, for example, communities of interests or communities of relationships. Building upon the art of successful online teachers (Salmon, 2002), instructors emphasized this quality in the design and delivery of courses.

I wanted people to have some individual opportunities and I wanted them to have collaborative opportunities so that's how I set it up. (George, 5/2004)

While participants' indicated that communities are built from cooperative and collaborative practice, instructors hoped this would emerge in 
their courses. To encourage this, all participants included some aspect of collaborative group, team, project or presentation work in their course designs. It was important for instructors to see whether their ideas for course content, processes and design were working as intended. Salmon (1999) indicates that because online course development must be essentially completed in advance, participants in this study were interested in obtaining feedback from learners as they completed course tasks through the term.

\section{Conclusions \& Recommendations}

The six themes identified in the study suggest that faculty issues can have as much, or more influence on the way in which instructors experience the transition from face-to-face to online education. In this study, the way to help instructors move into a new way of teaching using an online teaching process goes beyond an orientation to online courses, and/or explanations of how learning software can serve the needs of the instructor, department or administration. For online teaching to be integrated and embraced by instructors, departments must provide multiple opportunities for faculty to find the support and information they need as and when required. Further, the encouragement of faculty to develop coping strategies individually and in small groups, helps to enable instructors to develop roles and identity as online instructors. Most importantly, however, this study indicates that organizational culture and context are essential components in the development of positive, clear and effective messages to faculty about teaching online courses. Faculties need to demonstrate that online teaching is desired, respected, accessible and flexible within the organizational culture of the university teaching environment.

This study is consistent with the findings of other studies (Betts, 1998; King, 2000; Quinn \& Corry, 2002; Salmon, 1999) related to online faculty development. A call for continuing professional education opportunities would be appropriate for continued development for online teaching just as continued professional education is offered for face-to-face teachers. Further, the development of a national training program built upon competency skills needed for the online teaching environment might be helpful to novice instructors across colleges and universities across Canada.

\section{References}

Baynton, M., Groen, J., Willment, J., \& Slater, L. (2003, December). The experiences of adult education instructors adapting to the online teaching and learning environment. Journal of Executive Education, 2(2), 39-49. 
Betts, K. S. (1998). An institutional overview: factors influencing faculty participation in distance education in postsecondary education in the United States. Online Journal of Distance Learning Administration, 1(3), 1-14.

Bredeson, P. V. (1993). Letting go of outlived professional identities: A study of role transition and role strain for principals in restructured schools. Educational Administration Quarterly, 29(1), 34-68.

Cranton, P. (1994). Understanding and promoting transformative learning. San Francisco: Jossey-Bass.

King, K. (2000). A journey of transformation: A model of educators' learning experiences in educational technology. Adult Education Research Conference 2002 Conference Proceedings (p. 195-200). Raleigh, N.C.

Lesser, E., Fontaine, M., \& Slusher, J. (Eds.). (2000). Knowledge and Communities. Boston: Butterworth Heinemann.

MacKeracher, D. (1996). Making sense of adult learning. Toronto, ON: Culture Concepts.

Merriam, S., \& Simpson, E. (1995). A guide to research for educators and trainers of adults ( $2^{\text {nd }}$ ed.). Malabar, FL: Krieger Publishing Company.

Mezirow, J., \& Associates (2000). Learning and transformation: Critical perspectives on a theory in progress. San Francisco: Jossey-Bass.

Quinn, L., \& Corry, M. (2002). Factors that deter faculty from participating in distance education. Online Journal of Distance Learning Administration, 5(4), 1-19.

Salmon, G. (2002). E-tivities. London: Kogan Page.

Salmon, G. (1999). E-moderating. London: Kogan Page. 